\title{
Entrevista - Will Straw e a importância da ideia de cenas musicais nos estudos de música e comunicação
}

\author{
Jeder Janotti Junior
}

A sistematização acadêmica da ideia de cena musical foi proposta por Will Straw como um modo diferencial de circulação de música nos tecidos urbanos. Inicialmente Straw procurou perceber as redes de sociabilidade que moldavam o consumo do rock alternativo e da dance music em cidades como Montreal, Toronto, Detroit, Los Angeles e Londres. Essa perspectiva procurava diferenciar comunidades musicais de cenas, apontando os aspectos ativos das últimas contra o engessamento geográfico das primeiras. Desde então, a ideia de cena se tornou gradativamente uma importante ferramenta para os estudos comunicacionais do consumo e da produção musical, ao mesmo tempo em que acabou gerando uma série de debates em relação ao seu alcance e, principalmente, sua limitação quando, segundo parte de seus críticos, privilegiaria os aspectos sociológicos das apropriações da música em detrimento de seus aspectos estéticos.

Jeder Janotti Junior | jederj@@gmail.com Doutor em Ciências da Comunicação pela Universidade do Vale do Rio dos Sinos (UNISINOS). Pesquisador CNPq e professor do Programa de Pós-Graduação em Comunicação da Universidade Federal de Pernambuco (UFPE).
Em generosa entrevista concedida em março ao professor Jeder Janotti Jr, do Programa de Pós-Graduação em Comunicação da Universidade Federal de Pernambuco, Will Straw atualiza e reconsidera uma série de pontos polêmicos que ainda configuram os debates em torno da ideia de cenas musicais. Como é possível perceber em suas respostas, Straw mostra como sua proposta tenta dar conta das relações formadas na circulação global da música popular massiva, sem deixar de lado possíveis encaixes com circulações restritas e referências regionalizadas. Antes de afirmar a validade de uma noção rígida de cena, o pesquisador canadense reconhece que tal como o consumo e a produção de música, a noção de cenas musicais também passou por transformações significativas nos últimos tempos.

Como mostram as respostas de Straw, com o passar do tempo e o desenvolvimento das redes sociais dedicadas à música, a noção de cena passou por mudanças, adquirindo novas possibilidades e importância dentro dos estudos de música e comunicação. Afinal, como toda noção produtiva, a ideia de cena teve de ser ampliada para abarcar as transformações que atingiram 0 
mundo da música ao longo da primeira década do século XXI.

Jeder Janotti Júnior: Prezado Will Straw, após tantos anos de contribuição dos estudos culturais e da comunicação para os estudos sobre música popular como você avalia o atual cenário acadêmico desses estudos?

Will Straw - Acho que podemos apontar duas tendências. Por um lado, existe a reconhecida riqueza dos estudos de música popular, manifesta em sua saúde institucional, na proliferação de publicações, programas, etc. Por outro lado, está a percepção, expressa por alguns, de que o campo perdeu algo de seu entusiasmo e caráter inovador.

Minha opinião pessoal é de que o campo dos estudos de música popular hoje se caracteriza por muita pesquisa de alta qualidade. Boa parte dela é histórica. Agora dispomos de ótimos trabalhos históricos sobre fenômenos como a música disco de Nova Iorque dos anos 1970, o samba e outros gêneros brasileiros, a cultura mod britânica, música popular francesa do século XIX, música noise japonesa, etc.

A meu ver, o que, no entanto, diminuiu foi o clima de polêmica, de debate vívido a respeito de conceitos chave dos estudos de música popular. Os debates mais antigos relativos a autenticidade foram, em grande medida, concluídos, pois praticamente todo mundo concorda que a autenticidade é "socialmente construída" (ideia convincente, porém não muito útil). Da mesma forma, a questão da relação entre música e lugar resultou no amplo reconhecimento de que se trata de algo variado e complexo. Os debates sobre a relação entre música e novas mídias estão, a meu ver, ocupados demais em correr atrás do desenvolvimento atual no campo das novas mídias para produzir algum vocabulário conceitual de valor duradouro.

Acredito que, para os estudos de música popular, o risco é de que suas questões mais interessantes sejam assumidas por outros campos. O campo dos "estudos do som", por exemplo, no momento está muito mais animado do que o de estudos de música popular na América do Norte, graças, em parte, à obra de meu amigo e colega Jonathan Sterne. Outros aspectos da música popular são estudados dentro de uma análise mais ampla das inovações tecnológicas, como na produção acadêmica da antropóloga britânica Georgina Born. E muito do melhor trabalho sobre música popular está surgindo nos escritos de antropólogos como Ana Ochoa, cuja principal identificação não é com estudos de música popular.

Jeder Janotti Júnior: Após mais de vinte anos de sua primeira publicação sobre as cenas musicais, como você observa a atualidade dessa ideia? 
Will Straw - A meu ver, a noção de cena desenvolveu-se em duas direções nos últimos vinte anos. Em uma delas, "cena" é um elemento em uma série lexical que inclui "subcultura", "tribo" e outras unidades sociais/ culturais nas quais se supõe que a música exista. O conhecido trabalho de Andrew Bennett, David Hesmondhalgh e outros se preocupou em determinar qual dessas unidades é mais útil no estudo da música. Em outra direção, recorrese à "cena" para tentar teorizar a relação $d a$ música com a geografia, o espaço. Aqui eu apontaria o trabalho seminal de Barry Shank e Holly Kruse, mas também a pesquisa de Chris Gibson, Geoff Stahl e outros a respeito de cidades ou outras regiões. Eu ressaltaria que o trabalho brasileiro é forte em ambas as direções - na análise de categorias sociais e na concepção das maneiras como as práticas musicais articulam um sentido de espaço.

Pessoalmente, penso duas coisas. Uma é que a ideia de cena pode ser proveitosamente revitalizada por meio de um desvio que passe por outros trabalhos sobre cultura urbana em sentido mais geral. Estou pensando no artigo de Alan Blum sobre cenas em seu livro "The Imaginative Structure of the City", no qual o autor liga a noção de cena a um sentido mais amplo da teatralidade pública e da visibilidade da cultura urbana. Em outras palavras, o sentido de "cena" como "aquilo que é cena" precisa ser mais desenvolvido. A este respeito, também estou interessado no modo como a cena se encaixa na espécie de cultura pública que os historiadores consideram como tendo emergido nas cidades ocidentais no século XX: uma cultura pública descrita por Guillaume Pinson e outros historiadores franceses em termos da categoria de "mundano", da "palavra", da sociabilidade pública de artistas e boêmios.

Ao mesmo tempo, penso que cena tem muito a ganhar com um diálogo mais estrito com teorias de redes e infraestruturas. Em particular, acho que precisamos dar mais atenção ao papel das instituições de nível mais baixo como bares, lojas, locais de criação de redes por meio das quais as práticas musicais e as pessoas circulam. A noção de "cena" não precisa ter agentes humanos ativos em seu centro; também pode referir-se a redes, nodos e trajetórias de circulação.

Jeder Janotti Júnior: A noção de cena surgiu em um momento de tensão entre os estudos de caráter musicológico e comunicacionais da música popular? Em que medida esta ideia atravessou esse antigo debate? Ele ainda se mantém?

Will Straw - Bem, parece-me bem claro que a noção de cena afastou partes importantes dos estudos de música popular da musicologia e em direção à geografía e antropologia culturais. As preocupações com autenticidade e identidade que marcaram a onda inicial de estudos de música popular prestaramse a análises tanto musicológicas quanto 
sociológicas, ao passo que as análises de cenas geralmente tinham pouco a dizer a respeito de forma e estilo musicais. No entanto, à medida que os estudos de música popular começaram a ocupar um lugar mais forte entre faculdades de música do mundo inteiro, passou a ser mais provável que os "estudos de cena" coexistissem com análises musicológicas mais convencionais.

A exemplo dos estudos subculturais das décadas de 1970 e 1980, a "virada" geográfica dos estudos de música popular dos anos 1990 e 2000 deu aos estudiosos da música popular, na falta de formação acadêmica em análise musical, ricos materiais conceituais com os quais trabalhar.

\section{Jeder Janotti Júnior: Em que medida a ideia} de cena musical permanece viva quando se olha para o atual circuito de música ao vivo e para a circulação de música na internet?

Will Straw - Esta é uma pergunta importante à qual outros talvez estejam mais qualificados do que eu para responder. Sei que, nos primórdios da internet, houve tentativas de superpor estudos de comunidades musicais baseadas na internet à ideia de cena. Dado que muitas definições de cena incluem a noção de redes com dispersão internacional nas quais o contato face a face é mínimo, não chega a ser uma surpresa a tentativa de usar cenas na descrição de formas de interação baseadas na internet. Minha opinião pessoal é que esse encontro entre estudos de cena e estudos de música na internet não produziu muito que possa ser considerado inovador.

Jeder Janotti Júnior: As cidades ainda são o grande referencial para a análise das apropriações dos produtos culturais?

Will Straw - Em muitos aspectos, o imenso boom nos estudos de cultura urbana a partir da década de 1990 ofereceu-nos um conjunto muito mais rico de ferramentas para analisar o consumo cultural. Em particular, forçou-nos a ampliar o escopo de nossas análises para além do simples encontro entre o cidadãoconsumidor e o objeto-texto. No contexto urbano, somos obrigados a considerar a circulação de bens culturais e a variedade de pontos-geográficos, institucionais, econômicos e afetivos - nos quais esses bens encontram usuários e consumidores. Isso aproximou os melhores estudos culturais de uma antropologia culturais urbana, produzindo alguns trabalhos excelentes.

Ao mesmo tempo, o viés urbano persiste nos estudos culturais, e sabemos pouquíssimo sobre o consumo de artefatos culturais em áreas rurais ou outras não urbanas.

Jeder Janotti Júnior: Boa parte das críticas à ideia de cena apontam para a falta de sistematização metodológica, o que você acha deste ponto? 
Will Straw - Como já afirmei, a falta de metodologia rigorosa é intrínseca à noção de "cena" na medida em que a natureza dos laços que esta postula entre várias práticas, estilos e valores nunca pode ser engessada em uma fórmula. Pode-se resolver isto descrevendo esses laços em termos muito específicos em estudos de casos individuais (que, no entanto, podem ser pouco aplicáveis a outros exemplos) ou mantendo o termo em sua acepção pouco definida. Prefiro esta última solução; o termo pode servir como uma espécie de significante flutuante dentro de outros marcos de análise (como a teoria da circulação ou teoria do atorrede) no intuito de equilibrar a tendência desses marcos a produzirem modelos excessivamente rígidos de prática cultural. Como apontei, "cena" requer que se passe da prática localizada a uma conceituação mais ampla de sociabilidade cultural e teatralidade.

\section{Jeder Janotti Júnior: Que dicas você daria para quem está iniciando um trabalho sobre cenas e quer evitar as armadilhas de uma etnografia do gosto pessoal?}

Will Straw - Eu sugeriria dois procedimentos:

(1) Comece por des-subjetivar a análise. Quer dizer, não comece pelos fãs de música e músicos e pelo que eles fazem. É melhor começar por alguma substância (um gênero de música, por exemplo) ou categoria de evento (a execução de música) e continue por meio das várias redes de pessoas, objetos, lugares e circuitos culturais que a sustentam e produzem. Lembre-se de que todo mundo entra em uma cena em um determinado ponto de sua constituição e desenvolvimento. As cenas não são criadas coletivamente em um momento de atividade compartilhada $e$ participativa que expresse diretamente os valores daquela coletividade.

(2) Proceda sempre por comparação. Compare uma cena musical com outra para desfamiliarizar ambas. Ou - o que é ainda melhor - compare a cena musical com as atividades e infraestruturas sociais que se formam em torno de certas atividades não musicais (como trabalho acadêmico, atividade religiosa, moda, etc.).

\section{Jeder Janotti Júnior: Além da abordagem etnográfica e das práticas de consumo, como podemos estudar as cenas musicais?}

Will Straw - Já mencionei algo disto, mas eu começaria vendo de que maneira as cenas tratam o que Friedrich Kittler definiu como algumas das funções essenciais da mídia: "armazenamento, transmissão e processamento." Os indivíduos talvez não participem de nenhuma delas conscientemente, mas a cena como um todo é um sistema destinado a lembrar, movimentar e transformar a expressão cultural e a energia social. Tome distância dos indivíduos e analise a midialidade da cena nos termos que indiquei. 
Jeder Janotti Júnior: Inicialmente você articulou as noções de campo (Bourdieu), lógica social das mercadorias culturais (Miége) e práticas cotidianas (De Certeau) para analisar a existência das cenas musicais. Essa articulação permanece atual?

Will Straw - Em um nivel fundamental, continuo sendo bourdieusiano no sentido de que acredito que a cultura desenvolve-se principalmente por meio de princípios de diferenciação que estão ligados a uma lógica do avanço social. Quando escrevi meu primeiro artigo sobre cena, Miège era importante por preocupar-se com commodities culturais e com seu modo de circulação e valorização. Muitas dessas preocupações foram absorvidas pela antropologia da circulação apresentada por Gaonkar e Povinelli, que constituem talvez a influência mais importante sobre meu pensamento recente a respeito do tema. A influência de Certeau tornou-se menos direta, apesar de meu gosto por sua escrita. Eu até diria que, na minha invocação original de Certeau, havia pouco que também não estivesse presente em Bourdieu.

Jeder Janotti Júnior: No início dos anos 2000 muito se falou das cenas virtuais e de uma suposta decadência das cenas urbanas, o que você achou desse debate? Ele ainda permanece?

Will Straw - Acho que devemos separar certa globalização das cenas de sua virtualização.
Ao pensar, por exemplo, na cena eletrônica em Montreal associada com o Festival Mutek e suas várias atividades, podemos ver que eles levaram sua "marca" ao mundo inteiro, e que o evento em Montreal inclui colaboradores habituais que vêm de longe. Sob certos aspectos, isto difere pouco do que era comum no jazz nas décadas de 1960/1970, ou na música clássica durante a maior parte do século XX. Assim, embora eu ache que há uma intensificação da globalização musical, e isto está clara e estreitamente relacionado com a internet, não tenho certeza de que um modelo mais antigo de globalização seja menos pertinente.

Ao mesmo tempo, a música está, mais do que nunca, inserida em um lugar. Os festivais de música são mais importantes do que em qualquer outro momento da história, e a vida dos clubes, locais e shows ainda éforte. Em meu primeiro artigo sobre as cenas, falei da replicação de uma série de gostos em um lugar depois do outro. Acho que isto continua acontecendo, e os estilos musicais podem ser de caráter cosmopolita e circulante, mas os eventos musicais ainda estão muito ligados ao local.

Jeder Janotti Júnior: Outra crítica envolve a abrangência do termo, muitas vezes há referências a cenas locais, cenas nacionais ou cenas globalizadas. Para você esta distinção existe? Há uma ideia comum que está presente nas diferentes utilizações do termo cena? 
Will Straw - A noção de cena, em si, não resolverá o problema dos níveis - da relação do local com o nacional e o internacional. A pertinência de qualquer definição de cena será construída dentro de trabalhos individuais de análise.

O meu interesse é nas cenas como fenômenos urbanos, na medida em que interagem com outras cenas urbanas para produzir as texturas complexas da cultura urbana. Se estivesse mais interessado na circulação transurbana de estilos e afinidades musicais, eu poderia, ou não, adotar a noção de "cena". A pertinência da noção de "cena" nessas análises dependerá do caráter convincente da análise, de sua capacidade de mostrar como diferentes níveis de "operação" ou comunicação compartilham certas características.

\section{Jeder Janotti Júnior: Em que medida as recentes transformações na circulação de música afetaram a ideia de cena musical?}

Will Straw - Em sentido muito banal, o declínio das lojas de música, revistas de música e outras "instituições" de música mudou, obviamente, o significado de dedicar-se à música e adquirir, de forma cotidiana, música ou informação a seu respeito. Ao mesmo tempo, acredito que o ascenso de uma cultura audiovisual baseada na internet tornou a música menos importante na vida das pessoas, e que esta tendência pode ser de longo prazo, com importantes consequências para a noção de cena musical. Se uma cena musical é a vida-mundo em que as pessoas, em momentos importantes de suas vidas, passam boa parte do tempo, então podemos ver as cenas recuando em termos de sua importância cultural e sociológica. (Meus estudantes de pós-graduação que, uma década atrás, estavam intensamente envolvidos com música, hoje estão igualmente dedicados a séries de televisão e à cultura dos restaurantes!)

Quando as cenas se baseavam na noção de escassez musical - na dificuldade de encontrar música do tipo que você gostava, ou pessoas com gosto semelhante - as cenas tornaram-se importantes refúgios e recursos para as pessoas. Agora que não é mais assim, acho que a especificidade das cenas musicais será perdida. Ao mesmo tempo, aumentou a importância de uma forma voltada para a cultura/boêmia de viver nas cidades, e as cenas musicais sobreviverão como subconjuntos desses estilos de vida.

Jeder Janotti Júnior: A ideia de cena, desde seu surgimento, esteve atrelada ao jornalismo e à crítica cultural, a noção de crítica musical parece estar se transformando. Isso afeta a função de nomeação das cenas que antes parecia ser papel da crítica?

Will Straw - Ainda acho que as cenas se apoiam na identificação e documentação das atividades musicais, que continuam. A "cena" de Montreal dos últimos quinze anos continua a ser alvo de intensa cobertura da imprensa, 
de blogs e da mídia social. Estilos recémsurgidos, como Chicago Footwork, ou cenas que há pouco se tornaram hype, como U.S. dubstep, ainda são objeto de tipos antiquados de pesquisa de tendência e identificação. 0 aprendizado da história e dos valores da forma musical continua sendo uma parte essencial do envolvimento com a música, o que foi muito facilitado pelo YouTube, por grupos de afinidade do Facebook e outros aspectos das novas mídias.

O New York Times declarou recentemente que a internet tinha matado a ideia de esnobismo musical, abrindo a todos o acesso a qualquer tipo de música disponível, mas ainda sou bourdieusiano o bastante para pensar que as pessoas se reúnem em grupos em função de seus gostos, e esses grupos tendem à exclusividade.

Jeder Janotti Júnior: Inicialmente havia uma distinção entre comunidades e cenas musicais. Você acha que essa separação ainda continua válida? Vale a pena ainda falar de comunidades musicais? Por quê?

Will Straw - Em Mile End, o bairro de Montreal onde moro, há diversas comunidades formadas em torno da música que são fortes e se superpõem. O discurso de hipsterdom e as realidades da valorização cultural nas cidades do mundo todo deram destaque ainda maior à noção de comunidades musicais. Como já indiquei, estou menos interessado na noção de comunidade, pois esta tende a centrar-se exclusivamente nas relações entre pessoas (e não nas relações entre pessoas e lugares, coisas e processos). No entanto, como muitas teorias sociais interessantes se debruçam sobre a maneira como as pessoas coabitam os espaços urbanos do mundo contemporâneo (e o fazem em contextos de crescente diversidade étnica/racial/cultural), penso que a noção de comunidades musicais pode assumir nova importância.

Jeder Janotti Júnior: A noção de cena serve para toda e qualquer apropriação de música popular nas cidades ou ela continua restrita a grupos de consumidores específicos como os casos que você utilizou em seus primeiros escritos (rock alternativo e a cena dance)?

Will Straw - Claro que deve aplicar-se a um conjunto maior de estilos musicais. Na verdade, acho que o trabalho mais interessante sobre as cenas pode ser o que trate de formas e práticas não habitualmente consideradas como estando dentro do marco da "cena": Música clássica, por exemplo, ou os revivals da música swing dos anos 1940, ou música de igreja. A noção de cena é enriquecida quando os exemplos servem para derrubar os preconceitos (sobre o que é cool ou subcultural ou "tipo cena") que presidiram aos estudos de música popular.

Jeder Janotti Júnior: Há uma definição atual de Will Straw para cenas musicais nos dias atuais? Se sim, qual é essa definição? 
Will Straw - Existe algo de má fé em minha definição inicial. Como alguns apontaram, eu estava preocupado tanto com o movimento e 0 desenvolvimento de circuitos de estilos quanto com as espécies de mundos em que as pessoas viviam sua relação com a música. Este último interesse se tornaria o foco dos estudos sobre cena, gerando bastantes trabalhos interessantes (aliás, boa parte dos quais de intelectuais brasileiros).

Eu hoje definiria cena como as esferas circunscritas de sociabilidade, criatividade e conexão que tomam forma em torno de certos tipos de objetos culturais no transcurso da vida social desses objetos.

Contudo, isto não resolve nada! 


\section{Expediente}

A revista E-Compós é a publicação científica em formato eletrônico da Associação Nacional dos Programas de Pós-Graduação em Comunicação (Compós). Lançada em 2004, tem como principal finalidade difundir a produção acadêmica de pesquisadores da área de Comunicação, inseridos em instituições do Brasil e do exterior.

\section{E-COMPÓS I www.e-compos.org.br I E-ISSN 1808-2599}

Revista da Associação Nacional dos Programas

de Pós-Graduação em Comunicação.

Brasília, v.15, n.2, maio/ago. 2012.

A identificação das edições, a partir de 2008 ,

passa a ser volume anual com três números.

\section{CONSELHO EDITORIAL}

Afonso Albuquerque, Universidade Federal Fluminense, Brasil Alberto Carlos Augusto Klein, Universidade Estadual de Londrina, Brasil Álvaro Larangeira, Universidade Tuiuti do Paraná, Brasi André Luiz Martins Lemos, Universidade Federal da Bahia, Brasil Ângela Freire Prysthon, Universidade Federal de Pernambuco, Brasil Angela Cristina Salgueiro Marques, Faculdade Cásper Líbero (São Paulo), Brasil Antonio Roberto Chiachiri Filho, Faculdade Cásper Líbero, Brasil Arthur Autran Franco de Sá Neto, Universidade Federal de São Carlos, Brasil Benjamim Picado, Universidade Federal Fluminense, Brasil César Geraldo Guimarães, Universidade Federal de Minas Gerais, Brasil Cristiane Freitas Gutfreind, Pontifícia Universidade Católica do Rio Grande do Sul, Brasil

Denilson Lopes, Universidade Federal do Rio de Janeiro, Brasil Eduardo Peñuela Cañizal, Universidade Paulista, Brasi Eduardo Vicente, Universidade de São Paulo, Brasil Eneus Trindade, Universidade de São Paulo, Brasil Florence Dravet, Universidade Católica de Brasília, Brasil Gelson Santana, Universidade Anhembi/Morumbi, Brasil Gislene da Silva, Universidade Federal de Santa Catarina, Brasil Guillermo Orozco Gómez, Universidad de Guadalajara Gustavo Daudt Fischer, Universidade do Vale do Rio dos Sinos, Brasil Hector Ospina, Universidad de Manizales, Colômbia Herom Vargas, Universidade Municipal de São Caetano do Sul, Brasil Inês Vitorino, Universidade Federal do Ceará, Brasil Jay David Bolter, Georgia Institute of Technology Jeder Silveira Janotti Junior, Universidade Federal de Pernambuco, Brasil John DH Downing, University of Texas at Austin, Estados Unidos José Afonso da Silva Junior, Universidade Federal de Pernambuco, Brasil José Carlos Rodrigues, Pontifícia Universidade Católica do Rio de Janeiro, Brasi José Luiz Aidar Prado, Pontifícia Universidade Católica de São Paulo, Brasil Kelly Cristina de Souza Prudêncio, Universidade Federal do Paraná, Brasil. Laan Mendes Barros, Universidade Metodista de São Paulo, Brasil
Lance Strate, Fordham University, USA, Estados Unidos

Lorraine Leu, University of Bristol, Grã-Bretanha

Lucia Leão, Pontifícia Universidade Católica de São Paulo, Brasil

Malena Segura Contrera, Universidade Paulista, Brasil

Márcio de Vasconcellos Serelle, Pontifícia Universidade Católica de Minas Gerais, Brasil

Maria Aparecida Baccega, Universidade de São Paulo e Escola Superior de Propaganda e Marketing, Brasil

Maria Ataide Malcher, Universidade Federal do Pará, Brasi

Maria das Graças Pinto Coelho, Universidade Federal do Rio Grande do Norte, Brasil

Maria Immacolata Vassallo de Lopes, Universidade de São Paulo, Brasil Maria Luiza Martins de Mendonça, Universidade Federal de Goiás, Brasi Mauro de Souza Ventura, Universidade Estadual Paulista, Brasil Mauro Pereira Porto, Tulane University, Estados Unidos Mirna Feitoza Pereira, Universidade Federal do Amazonas, Brasil Nilda Aparecida Jacks, Universidade Federal do Rio Grande do Sul, Brasil Osvando J. de Morais, Universidade de Sorocaba, Brasil Potiguara Mendes Silveira Jr, Universidade Federal de Juiz de Fora, Brasil Renato Cordeiro Gomes, Pontifícia Universidade Católica do Rio de Janeiro, Brasil Robert K Logan, University of Toronto, Canadá

Ronaldo George Helal, Universidade do Estado do Rio de Janeiro, Brasil Rose Melo Rocha, Escola Superior de Propaganda e Marketing, Brasil Rossana Reguillo, Instituto de Estudos Superiores do Ocidente, Mexico Rousiley Celi Moreira Maia, Universidade Federal de Minas Gerais, Brasil Sebastião Guilherme Albano da Costa, Universidade Federal do Rio Grande do Norte, Brasil

Simone Maria Andrade Pereira de Sá, Universidade Federal Fluminense, Brasil Tiago Quiroga Fausto Neto, Universidade de Brasília, Brasil Suzete Venturelli, Universidade de Brasília, Brasil Valerio Fuenzalida Fernández, Puc-Chile, Chile Veneza Mayora Ronsini, Universidade Federal de Santa Maria, Brasil Vera Regina Veiga França, Universidade Federal de Minas Gerais, Brasil

\section{COMISSÃO EDITORIAL}

Adriana Braga I Pontifícia Universidade Católica do Rio de Janeiro, Brasil

Felipe Costa Trotta I Universidade Federal Fluminense, Brasi

CONSULTORES AD HOC

Adriana Amaral, Universidade do Vale do Rio dos Sinos, Brasil

Ana Carolina Escosteguy, Pontifícia Universidade Católica do Rio Grande do Sul, Brasi Claudia Azevedo, Universidade Federal do Estado do Rio de Janeiro, Brasil Gisela Castro, Escola Superior de Propaganda e Marketing, Brasil Luis Queiroz, Universidade Federal da Paraíba, Brasil Rodrigo Carreiro, Universidade Federal de Pernambuco, Brasil EDIÇÃO DE TEXTO E RESUMOS I Susane Barros SECRETÁRIA EXECUTIVA I Juliana Depiné EDITORAÇÃO ELETRÔNICA I Roka Estúdio TRADUÇÃo I Sieni Campos
COMPÓS I www.compos.org.br

Associação Nacional dos Programas de Pós-Graduação em Comunicação

Presidente

Julio Pinto

Pontifícia Universidade Católica de Minas Gerais, Brasil juliopinto@pucminas.br

Vice-presidente

Itania Maria Mota Gomes

Universidade Federal da Bahia, Brasil

itania@ufba.br

Secretária-Geral

Inês Vitorino

Universidade Federal do Ceará, Brasil

inesvic@gmail.com 